\title{
ASSESSMENT OF ALUMINUM FSW JOINTS USING ULTRASONIC TESTING
}

\begin{abstract}
The paper concerns aluminum joints made using friction stir welding. Although in the aerospace industry there is a tendency to replace metal components with composites, aluminum continues to be a valuable material. Its share in the aircraft structures is the biggest among all structural metals. Lots of aluminum components are made of sheets and most of them require joining. Friction stir welding is a relatively new joining technology, particularly with regard to the sheets having a thickness of $1 \mathrm{~mm}$ or lower. The paper is dedicated to non-destructive testing of such joints using ultrasonic inspection. It was found that ultrasonic testing allows for distinguishing between joints without material discontinuities, joint with material discontinuities at the advancing side and joint with discontinuities extending through the whole width of the stir zone. During research only horizontally aligned defects were taken into account.
\end{abstract}

Keywords: aluminum sheet, Friction Stir Welding, joints, non-destructive testing, ultrasonic testing

\section{Introduction}

Friction Stir Welding, FSW, is a technology of joining metals invented in the early 1990's by TWI Ltd in the United Kingdom [1]. The characteristic feature of the process is that the temperature of the joined material doesn't exceed the melting point. The scheme of the FSW process is presented in Fig. 1. The key component of a welding unit is an FSW tool. The flat part of the tool having contact with the external surface of welded components is called shoulder. The part of the tool working inside the material is called pin. The tool rotates and moves along a welding trajectory. The tool fulfills three functions. It heats the material, forces its movement around the axis of rotation, and prevents the material escaping outside the weld [2]. The sources of heat are friction between the tool and the material, and plastic strains of the mixed material. The experimental research by Morisada [3] showed that the material in front of the tool upon contacting the pin surrounds the pin several times and subsequently is left behind the tool. The material of FSW tool must retain high strength at welding temperatures. FSW tools designed for joining aluminum alloys are typically made of $\mathrm{H} 13$ steel or MP159 nickel-cobalt alloy. The sides of a weld are asymmetric. The side of the joint where rotational and translational speeds have the same direction is called the advancing side. The side of the joint where rotational and translational speeds have the opposite directions is called the retreating side. The conventional FSW process creates continuous joints. There is also a variant of FSW process called Refill Friction Stir Spot Welding, RFSSW, which creates spot welds [4]. RFSSW refills

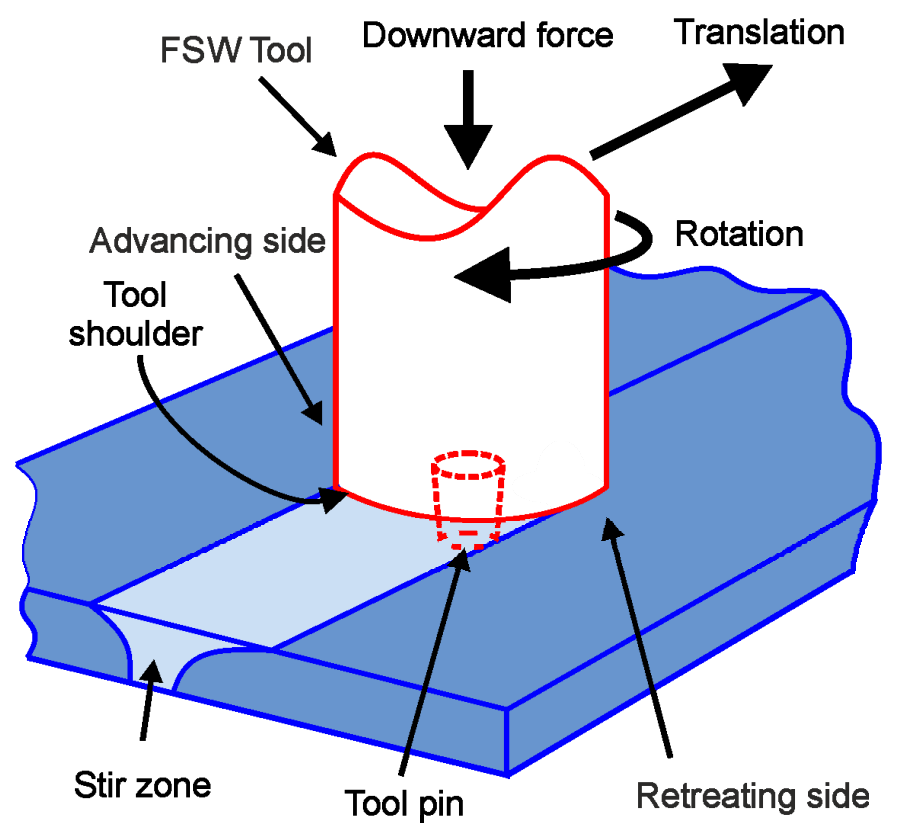

Fig. 1. The scheme of FSW process based on [5]. The sheets are in butt configuration

a hole produced by the tool exit from material and the resulting weld face is flat.

FSW is particularly suited for joining high strength aluminum alloys used in aviation. Application of fusion welding technologies to joining components made of aluminum $2 \mathrm{xxx}$ and $7 \mathrm{xxx}$ is avoided since these processes contribute to poor solidification microstructure and porosity in the fusion zone [6].

* CZESTOCHOWA UNIVERSITY OF TECHNOLOGY, 69 DĄBROWSKIEGO STR., 42-201 CZĘSTOCHOWA, POLAND

Corresponding author: Konrad.adamus@gmail.com 
The main drawback of riveting, which is the conventional method of joining high strength aluminum sheets, is that rivets increase the mass of a joint [7]. FSW produces high-quality aluminum joints without introducing additional materials. FSW is applied mainly in shipbuilding and railway industries to join thick aluminum panels. The aviation industry requires joining of thin aluminum sheets [8]. Only a few centers conduct research on joining sheets with the thickness lower than $1.0 \mathrm{~mm}$ [9-15].

Obtaining the good quality welds depends on many factors, primarily, on the process parameters, such as tool rotational speed and welding speed, which ensure the proper amount of frictional heat needed for material softening. Tool geometry is also very important because it affects both the amount of the generated heat and the effectiveness of material stir [16]. Unfortunately, due to significant frictional resistance [17], the tools wear out quickly, which adversely affects the quality of the welds [18, 19]. Typical defects present in FSW joints include a tunnel, a kissing bond, a hooking and a lack of penetration. The tunnel is a volumetric defect inside a weld extending along the welding trajectory. The kissing bond is a thin interlayer between two volumes having diminished strength. The hooking and the lack of penetration are related to the deformation of the oxide layer inside a weld. The hooking is present in overlap joints, the lack of penetration is present in butt joints.

There is a need for a non-destructive testing method that allows for detection of discontinuities in the joint [20-22]. Nondestructive testing of FSW joints includes visual testing, dye penetrant testing, eddy current testing, ultrasonic testing and radiographic testing [23]. Visual testing and dye-penetrant testing allow for identification of surface-breaking defects. Eddy current is suited for detection of subsurface defects aligned in the perpendicular direction to the tested surface. Radiographic testing enables identification of volumetric defects. Its accuracy is diminished when defects have the shape of narrow gaps parallel to the tested surface. Ultrasonic testing allows for detecting interfaces reflecting acoustic waves. It enables detecting volumetric defects. Identification of kissing bond defects is difficult [24]. Conventional ultrasonic methods allow for testing components having section thickness greater than $6 \mathrm{~mm}$ (PN-EN 10160:2001). In the context of FSW joints in the aviation industry, there is a need for the development of ultrasonic methods detecting defects in joints having thickness below $2 \mathrm{~mm}$.

\section{Goal and scope of tests}

The main goal of this work is to analyze the feasibility of application of ultrasonic testing to detection of material discontinuities in thin joints welded using FSW technology. The analyzed joints comprise two sheets: one having the thickness of $1.0 \mathrm{~mm}$ made of aluminum 2024 and the other having the thickness of $0.6 \mathrm{~mm}$ made of aluminum D16UTW. The main alloying elements of aluminum 2024 include copper and magnesium. The chemical composition of alloy 2024 according to EN 573-3:2013 is presented in Table 1. D16 alloy is the Russian counterpart of 2024 alloy. The chemical composition of D16 alloy is described by GOST 4784-74 specification. UTW grade of D16 alloy denotes that D16 sheets were coated with an anticorrosive layer made of pure aluminum.

TABLE 1

Chemical composition of alloy 2024 according to EN 573-3:2013

\begin{tabular}{|c|c|c|c|c|c|c|c|c|c|}
\hline Si & $\mathbf{F e}$ & $\mathbf{C u}$ & $\mathbf{M n}$ & $\mathbf{M g}$ & $\mathbf{C r}$ & $\mathbf{Z n}$ & $\mathbf{T i}$ & Other & Al. \\
\hline 0.5 & 0.5 & $3.8-4.9$ & $0.3-0.9$ & $1.2-1.8$ & 0.1 & 0.25 & 0.15 & $0-0.15$ & $\begin{array}{c}\text { re- } \\
\text { mainder }\end{array}$ \\
\hline
\end{tabular}

Ultrasonic tests were performed for selected FSW joints. Table 2 summarizes the research that was carried out. Four joints identified by symbols A-D were chosen for ultrasonic inspections. All joints comprised two aluminum sheets welded in an overlap configuration i.e. one of the sheets is on the top of the other. The geometry of the overlap joints is presented in Fig. 2. In joints A, B and D the sheet made of aluminum 2024 was at the top, whereas in joint $\mathrm{C}$ the sheet made of aluminum D16UTW was at the top. Joint A was free of defects at the interface between the sheets. In joints $B$ and $D$ there were defects at the advancing side of the interface between the sheets. In joint $C$ there were defects at both the advancing and the retreating side of the interface between the sheets.

TABLE 2

Ultrasonic tests of the overlap FSW joints

\begin{tabular}{|c|c|c|c|c|}
\hline \hline $\begin{array}{c}\text { Joint } \\
\text { ID }\end{array}$ & Top sheet & Bottom sheet & $\begin{array}{c}\text { Defects at the } \\
\text { interface } \\
\text { between sheets }\end{array}$ & $\begin{array}{c}\text { Scanning } \\
\text { mode }\end{array}$ \\
\hline $\mathrm{A}$ & $\begin{array}{c}2024, \\
1.0 \mathrm{~mm}\end{array}$ & $\begin{array}{c}\text { D16UTW, } \\
0.6 \mathrm{~mm}\end{array}$ & None & A mode \\
\hline B & $\begin{array}{c}2024, \\
1.0 \mathrm{~mm}\end{array}$ & $\begin{array}{c}\text { D16UTW, } \\
0.6 \mathrm{~mm}\end{array}$ & $\begin{array}{c}\text { At the advancing } \\
\text { side }\end{array}$ & A mode \\
\hline C & $\begin{array}{c}\text { D16UTW, } \\
0.6 \mathrm{~mm}\end{array}$ & $\begin{array}{c}2024, \\
1.0 \mathrm{~mm}\end{array}$ & $\begin{array}{c}\text { At the advancing } \\
\text { and retreating } \\
\text { sides }\end{array}$ & A mode \\
\hline $\mathrm{D}$ & $\begin{array}{c}2024, \\
1.0 \mathrm{~mm}\end{array}$ & $\begin{array}{c}\text { D16UTW, } \\
0.6 \mathrm{~mm}\end{array}$ & $\begin{array}{c}\text { At the advancing } \\
\text { side }\end{array}$ & C mode \\
\hline
\end{tabular}

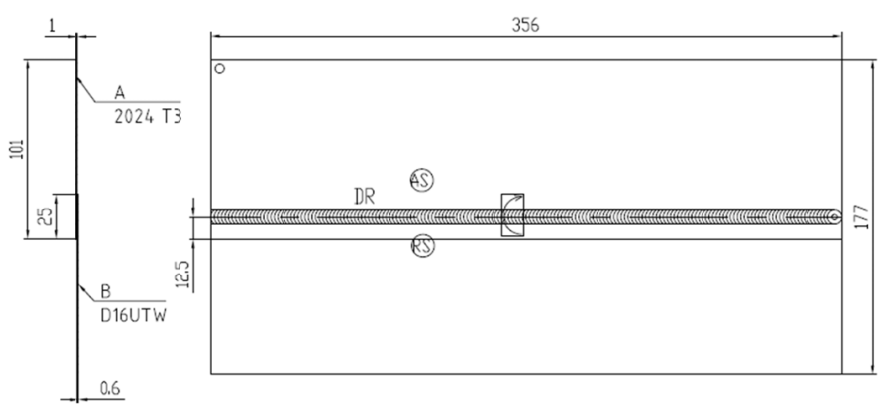

Fig. 2. The geometry of the overlap FSW joint

Ultrasonic tests were performed using two devices.

1. Joints A-C were tested using portable ultrasonic flaw detector USM36 equipped with CLF4 probe operating at 
the frequency of $15 \mathrm{MHz}$. CLF4 probe contains delay line between the transducer and the coupling face. Application of delay line allows for detecting near-surface flaws and testing of thin sections. The operating range of CLF4 probe is between 0.25 and $25 \mathrm{~mm}$. USM 36 flaw detector presents results in A mode i.e. waves reflected by analyzed objects are presented as echoes in a two-dimensional plot. Abscissa values denote the distance of a reflecting surface from the probe and ordinate values denote signal amplitudes. The testing station is presented in Fig. 3. To facilitate the propagation of acoustic waves through the interface between an FSW joint and the probe a thixotropic coupling paste was applied to the joint external surface.

2. Joint $\mathrm{D}$ was tested using portable ultrasonic flaw detector MiniScanner developed by Amsterdam Technology company. MiniScanner allows for testing sheets having the thickness greater than $0.6 \mathrm{~mm}$. Transducer operates at the frequency of $35 \mathrm{MHz}$. The results are presented in $\mathrm{C}$ mode i.e. the external surface of the tested object is presented as a map of colors where each color denotes the distance between the external surface and a surface reflecting the waves.

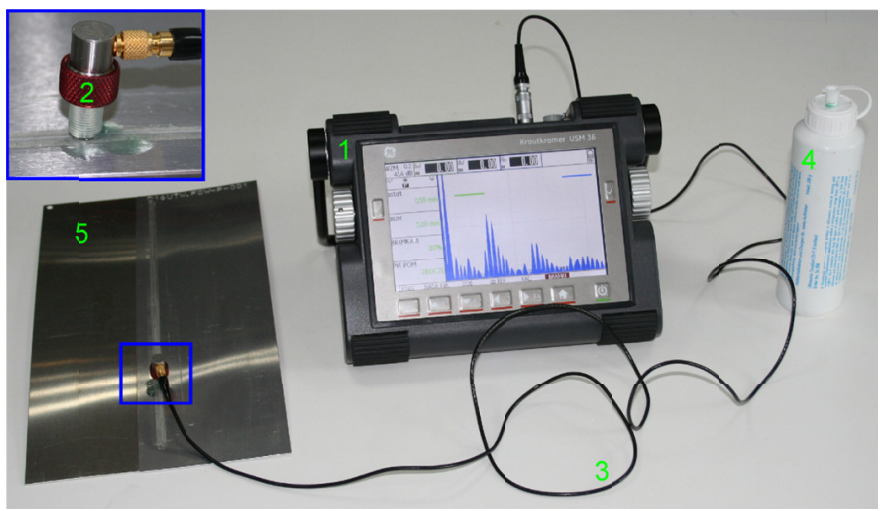

Fig. 3. Ultrasonic testing station: (1) the ultrasonic flaw detector USM36, (2) CLF4 probe, (3) the cable connecting the flaw detector and the probe, (4) the ultrasonic couplant, (5) an FSW joint

\section{Inspection of FSW joints with ultrasonic flaw detector USM36}

The cross-section of joint A is presented in Fig. 4(a). The dark region of the joint corresponds to the stir zone. The high temperatures and high strain rates contribute to material recrystallization and produce the fine-grained structure. The size of the recrystallization zone corresponds approximately to the size of the tool pin. The bottom sheet was coated with the anticorrosive layer made of pure aluminum. The aluminum layer can be seen as distinctly lighter strips along the edges of the bottom sheet. The aluminum layer inside the stir zone was pushed by the tool pin to the advancing side (the right side). The total thickness of joint cross-section is about $1.51 \mathrm{~mm}$.

The screenshot of the ultrasonic flaw detector showing the scan results for joint A was presented in Fig. 4(b). The range was set to $5 \mathrm{~mm}$, the gain was set to $41.6 \mathrm{~dB}$. The first peak represents the acoustic wave reflected at the interface between the probe and the joint. The second peak represents the wave reflected by the back wall of the joint i.e. the bottom surface of the bottom sheet. This is the first echo produced by the back wall. The third and fourth peak represent the second and the third back wall echo respectively. The depth of the back wall as measured by the gate $a$ is equal to $1.53 \mathrm{~mm}$. The gate $a$ is represented by a green color on the screen, the distance measured by the gate is denoted by Sa symbol. The flank measurement was chosen to determine the distance by gate $a$. The height of the pulses between back wall echoes is below $8 \%$ of the screen height.

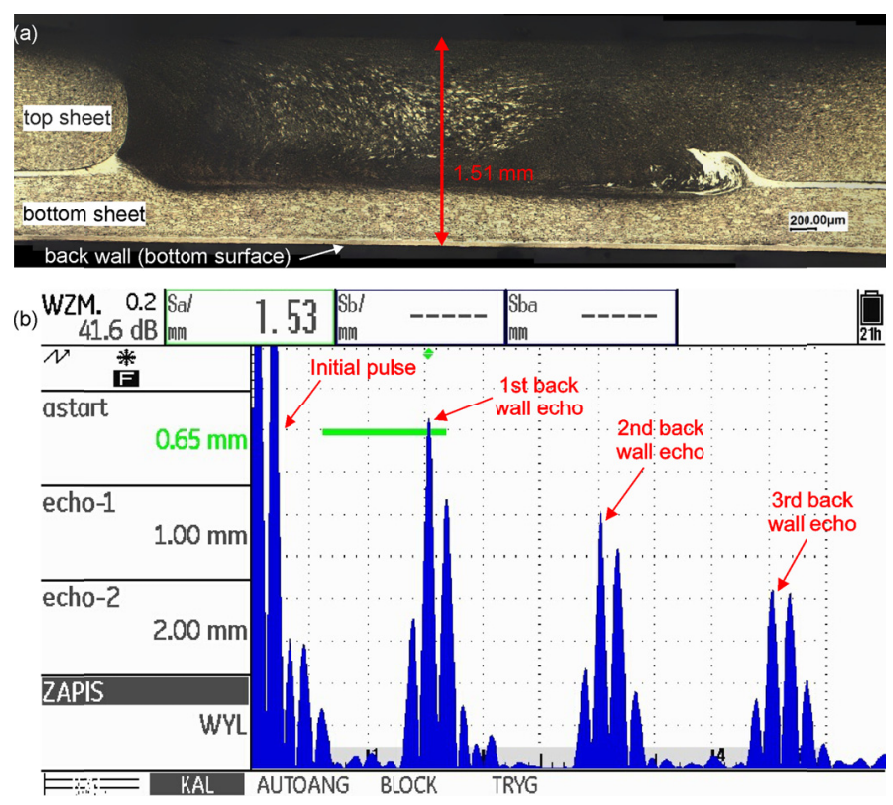

Fig. 4. Joint A with no discontinuities between the sheets: (a) crosssection, (b) ultrasonic A-scan results, gain $41.6 \mathrm{~dB}$

The cross-section of joint B is presented in Fig. 5(a). The five distinct tunnel defects can be seen in bottom part of the weld at the advancing side (the left side). The area with tunnel defects is denoted with a yellow dashed line. The thickness of the joint is about $1.45 \mathrm{~mm}$. The decrease of the joint B thickness relative to joint $\mathrm{A}$ thickness is the result of the joint thinning. The thinning is caused by the excessive tool plunging into the top sheet. The distance between the top surface and a tunnel defect is about $1.0 \mathrm{~mm}$.

The screenshot of the ultrasonic flaw detector showing the scan results for joint $\mathrm{B}$ was presented in Fig. 5(b). The range was set to $5 \mathrm{~mm}$, the gain was set to $47.4 \mathrm{~dB}$. Similarly to the scan results for joint $\mathrm{A}$, three echoes corresponding to the back wall can be seen. To achieve the same height of the first back wall echo the gain was increased relative to joint A scan by $5.8 \mathrm{~dB}$. The echo corresponding to the tunnel defects can be seen before the first back wall echo. Measurements performed by gate $a$ denoted with green color and $S a$ symbol indicate that the tunnel defects are at the depth of $1.04 \mathrm{~mm}$. The actual depth of the tunnels as measured in the metallographic specimen is equal to about $1.0 \mathrm{~mm}$. Measurements performed by gate $b$ 


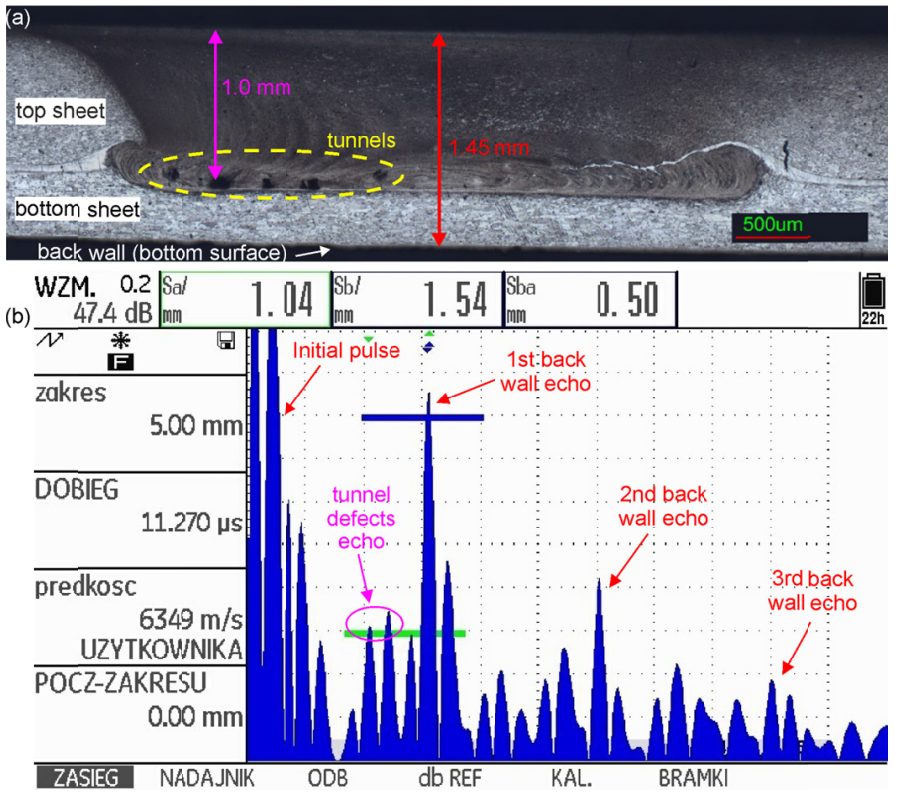

Fig. 5. Joint $B$ with tunnel defects at the advancing side (the left side): (a) cross-section, (b) ultrasonic A-scan results, gain $47.4 \mathrm{~dB}$

denoted with blue color and $S b$ symbol indicate that the joint thickness equals $1.54 \mathrm{~mm}$. The actual thickness as measured in the metallographic specimen is about $1.45 \mathrm{~mm}$. The presence of tunnel defects is correlated with additional echoes between the consecutive back wall echoes. The height of these echoes exceeds $20 \%$ of the screen height.

The cross-section of joint $\mathrm{C}$ is presented in Fig. 6(a). The extensive horizontally aligned tunnel going through the whole width of the stir zone can be seen in the bottom sheet. The tunnel was denoted with a yellow dashed ellipsis. The width of the weld face at the external surface of the top sheet was $6 \mathrm{~mm}$. The
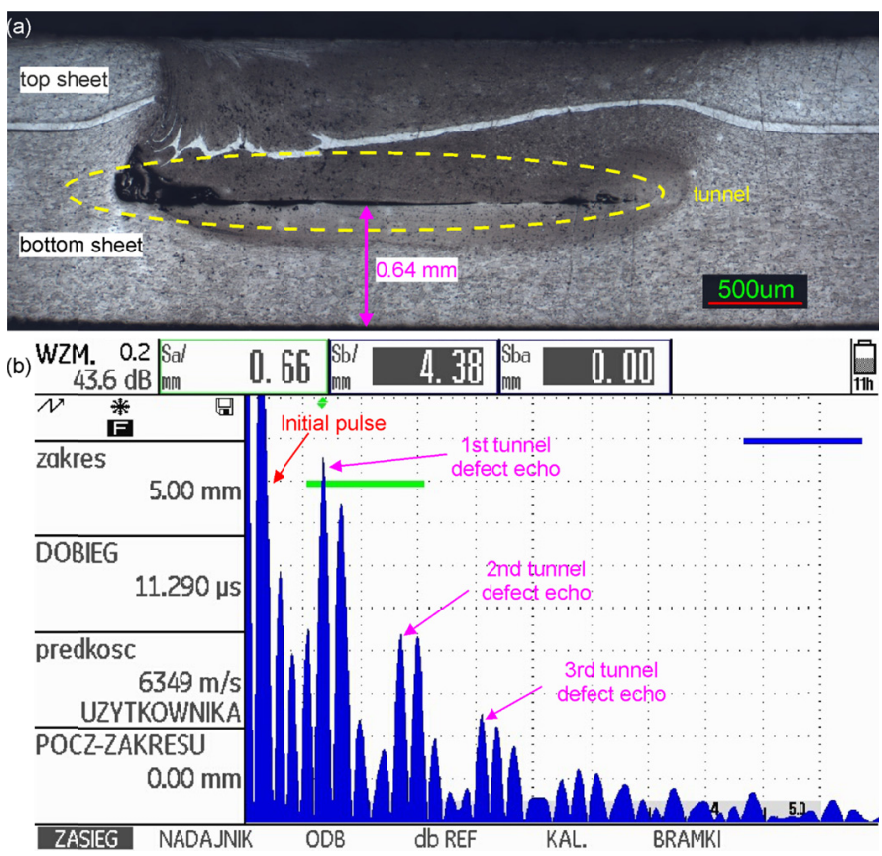

Fig. 6. Joint $C$ with tunnel defect through the whole width of the weld: (a) cross-section, (b) ultrasonic A-scan results, gain $43.6 \mathrm{~dB}$ action of the tool caused thinning of the joint and formation of the shallow flat depression. The diameter of the ultrasonic probe was $7.5 \mathrm{~mm}$. Since the probe diameter was greater than the width of the weld face and since the external surface near weld was uneven it was decided to perform measurements at the external surface of the bottom sheet.

The screenshot of the ultrasonic flaw detector showing the scan results for joint $\mathrm{C}$ was presented in Fig. 6(b). The range was set to $5 \mathrm{~mm}$, the gain was set to $43.6 \mathrm{~dB}$. Three echoes corresponding to the tunnel defect can be seen. The depth of the tunnel as measured by the gate a was equal to $0.66 \mathrm{~mm}$. The distance of the tunnel from the external surface of the bottom sheet as measured in the metallographic specimen was equal to $0.64 \mathrm{~mm}$. No distinct echo corresponding to the external surface of the top sheet can be observed. This is expected since the tunnel defect extends through the whole width of the stir zone. Between the echoes corresponding to the tunnel, additional echoes can be seen. The height of the additional echoes exceeds the $20 \%$ of the screen height. One of the causes of additional echoes might be the interference of the consecutive tunnel echoes or the uneven surface of the tunnel.

\section{Inspection of FSW joints with ultrasonic flaw detector MiniScanner}

Joint $\mathrm{D}$ was scanned by MiniScanner flaw detector. The scan results are presented in Fig. 7(a). The corresponding joint surface is shown in Fig. 7(b). The color map presented in Fig. 7(a) is created based on measurements in individual points within the scan area. The conventional A scan results, for instance, the results presented in Fig. 5(b), are transformed into colors based on the values of echo peaks in two gates. In the case of joint $\mathrm{D}$, one of the gates was set to detect echoes at the depth corresponding to the thickness of the top sheet. The red color was assigned to this gate. The other gate was set to detect echoes at the depth corresponding to the total joint thickness. The blue color was assigned to this gate. The intermediate depths were denoted with green color. The standard probe allows for scanning of the surface within a rounded rectangle. The obtained color map facilitates the assessment of the joint quality.

Material at the interface between the sheets should be joined within the volume of the weld. In the top view, the weld volume where the sheets were joined was denoted with a dashed blue line in Fig. 7(b). Since the acoustic waves propagate through the joined sheets and reflect at the bottom surface of the bottom sheet, this area should have the blue color in the scan results. If there are material discontinuities at the interface between the sheets, the acoustic waves won't propagate through the interface and will be reflected at the discontinuities. In this case, the area corresponding to the discontinuities should have the red color in the scan. The area of the joint $\mathrm{D}$ with discontinuities was denoted with a dashed magenta line in Fig. 7(b). Material at the interface between the sheets shouldn't be joined outside the volume of a weld. This area corresponds to material outside the region 
denoted with the blue dashed line and inside the region denoted with a red dashed line in Fig. 7(b). In the case of the sheets that are not joined at the interface, the waves reflect at the bottom surface of the top sheet. This area should have the red color in the scan results. The analysis of the scan results in Fig. 7(a) shows that there are discontinuities at the advancing side of the weld, denoted with the dashed magenta line in Fig. 7(b).
The results obtained by the scanning procedure were confirmed by the analysis of the joint cross section. The metallographic specimen of joint D is shown in Fig. 8. There are material discontinuities at the interface between the sheets at the advancing side of the weld. The depth of the defects measured by the MiniScanner was $0.9 \mathrm{~mm}$. The actual depth measured based on the metallographic specimen was $1.07 \mathrm{~mm}$.

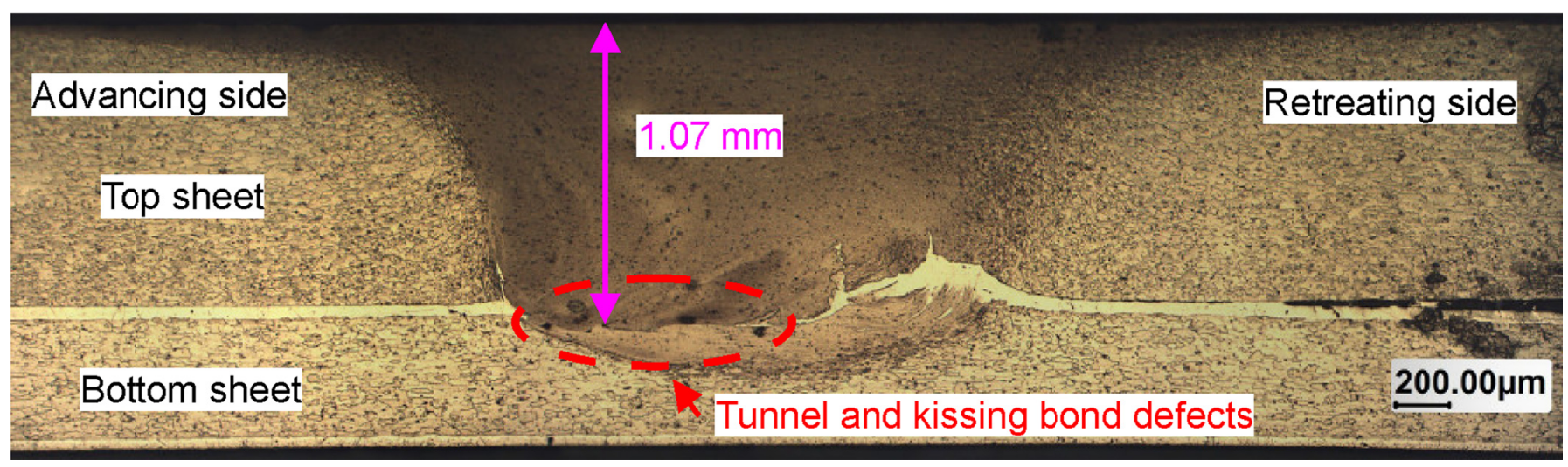

Fig. 8. Cross-section of joint $\mathrm{D}$

\section{Conclusions}

The following conclusion can be drawn based on the carried-out tests:

1. It is possible to detect material discontinuities in FSW overlap joints having total thickness of about $1.5 \mathrm{~mm}$ using ultrasonic flaw detectors.

2. Ultrasonic flaw detectors allow for identifying horizontally aligned defects such as tunnels and kissing bonds. No attempt was made to detect vertically aligned defects such as hooking.

3. It is possible to distinguish between the overlap joints:

a. without horizontal defects,

b. with horizontal defects at the advancing side,

c. with horizontal defects extending through the whole width of the stir zone.

4. Conventional ultrasonic flaw detector equipped with CLF4 probe operating at $15 \mathrm{MHz}$ presents the results measured at a single point using A scan. MiniScanner presents the results measured at an area using $\mathrm{C}$ scan in the form of a color map.

5. Since acoustic waves propagate in metallic materials, the same approach for nondestructive testing should be possible to apply for joints made of different alloys such as steels and titanium alloys.

\section{Acknowledgenets}

Financial support of The National Centre for Research and Development, European Union, PZL Mielec / a Sikorsky Company, in the framework of European Regional Development Fund Project „Advanced techniques for the fabrication of airframe structures using innovative friction stir welding (FSW) technology", no. INNOLOT/I/4/NCBR/2013 is gratefully acknowledged.

\section{REFERENCES}

[1] W.M. Thomas, E.D. Nicholas, J.C. Needham, M.G. Church, P. Templesmith, C.J. Dawes, Great Britain Patent Application No. 9125978.8 (1991).

[2] R.S. Mishra, P.S. De, N. Kumar, Friction stir welding and processing: Science and engineering, Springer (2014).

[3] Y. Morisada, H. Fujii, Y. Kawahito, K. Nakata, M. Tanaka, Scr. Mater. 65 (12), 1085-1088 (2011).

[4] P.A. Lacki, J.K. Winowiecka, A.M. Derlatka, Numerical and experimental analysis of aluminium Refill Friction Stir Spot Welding joints, in: E. Oñate, D.R.J. Owen, D. Peric, M. Chiumenti (Eds.), Proceedings of the 8th International Conference on Computational Plasticity - Fundamentals and Applications (2015).

[5] A.H. Plaine, N.G. Alcântara, Mat. Res. 17 (5), 1324-1327 (2014).

[6] R. Mishra, Z. Ma, Mater. Sci. and Eng. 50, 1-78, (2005).

[7] T. Sadowski, T. Balawender, R. Śliwa, P. Golewski, M. Kneć, Arch. Metall. Mater. 58 (1), 163 (2013).

[8] P. Lacki, J. Adamus, T. Sadowski, K. Wojsyk, M. Kneć, Friction Welding of the bars made of aluminium and titanium alloys, in: Eberhardsteiner et.al. (Eds.), Proceedings of the European Congress on Computational Methods in Applied Sciences and Engineering (ECCOMAS 2012), Vienna-Austria (2012).

[9] A. Derlatka, P. Kasza, Adv. Mat. Res. 1020, 151-157 (2014).

[10] A. Derlatka, P. Kasza, Adv. Mat. Res. 1020, 158-164 (2014).

[11] P. Lacki, A. Derlatka, Meccanica 51 (2), 455-462 (2016). 
[12] M.I. Costa, D. Verdera, J.D. Costa, C. Leitao, D.M. Rodrigues, J. Mater. Process. Tech. 225, 385-392 (2015).

[13] H. Chena, L. Fua, P. Liang, J. Alloy Compd. (2016) http://dx.doi. org/10.1016/j.jallcom.2016.08.330 (in press).

[14] F. Yusofa, A. Firdaus, M. Fadzil, M. Hamdi, Ultra Friction Stir Welding (FSW) between Aluminium Alloy and Copper, in Proceedings of the 1st International Joint Symposium on Joining and Welding, Osaka-Japan, 219-224 (2013).

[15] T. Mira-Aguiar, D. Verdera, C. Leitão, D.M. Rodrigues, J. Mater. Process. Tech. 238, 73-80 (2016).

[16] P.L. Threadgill, A.J. Leonard, H.R. Shercliff, P.J. Withers, Int. Mater. Rev. 54 (2), 49-93 (2009).

[17] J. Adamus, The influence of friction and lubrication on sheet-aluminium forming process. Proceedings of the 14th International Colloquium Tribology: Tribology and Lubrication Engineering, Esslingen-Germany (2004)
[18] A. Pietras, M. S. Węglowski, Bulletin of the Welding Institute in Gliwice-Poland, 58 (2), 23-32 (2014).

[19] B. Li, Y. Shen, W. Hu, Materials and Design 32, 2073-2084 (2011).

[20] B. Raj, T. Jayakumar, M. Thavasimuthu, Practical non-destructive testing, Woodhead Publishing (2002).

[21] T. Santos, P. Vilaça, L. Quintino, Welding in the World 52/9, 30-37 (2008).

[22] A. Lewińska-Romicka, Non-destructive testing, Basic of defectoscopy (in Polish: Badania nieniszczące. Podstawy defektoskopii), WNT, Warszawa-Poland, (2001).

[23] B.T. Gibson, D.H. Lammlein, T.J. Prater, W.R. Longhurst, C.D. Cox, M.C. Ballun, K.J. Dharmaraj, G.E. Cook, A.M. Strauss, J. Manuf. Process. 16 (1), 56-73 (2014).

[24] S. Delrue, M. Tabatabaeipour, J. Hettler, K. van den Abeele, Ultrasonics 68, $71-79$ (2016). 